\title{
NEW CONCEPTS OF BREAST CANCER AETIOLOGY
}

\author{
Ariyaratne $\mathbf{M ~ H ~ J}{ }^{1}$, Dilesha $\mathbf{W ~ L}^{2}$ \\ ${ }^{1}$ Consultant Surgeon, Head, Department of Surgery, \\ Faculty of Medicine, University of Kelaniya. \\ ${ }^{2}$ Demonstrator, Department of Surgery, \\ Faculty of Medicine, University of Kelaniya.
}

\author{
M H J Ariyaratne \\ MBBS(Col), MS(Col), FRCS(Eng), FRCS(Ed) \\ Consultant Surgeon, Head, Department of Surgery, \\ Faculty of Medicine, \\ University of Kelaniya.
}

W L Dilesha MBBS

Demonstrator, Department of Surgery,

Department of Surgery, Faculty of Medicine,

University of Kelaniya.

Corresponding author:

M H J Ariyaratne

Address: 22A, Norris Avenue, Colombo 08

Telephone: 0777397373 / 0112688044

E-mail:mhjari@gmail

\section{Introduction}

Breast cancer is a cancer of the glandular breast tissue, which is a progressive disease. Globally it is the fifth most common cause of cancer deaths. In 2005, breast cancer caused 502,000 deaths throughout the world, accounting for $7 \%$ of cancer deaths and $1 \%$ of all deaths. Among women worldwide, breast cancer is the most common cause of cancer death (1).

Today breast cancer, like other forms of cancer, is considered to be the final outcome of multiple environmental and hereditary factors. These range from failure of immune surveillance, abnormal growth factors signaling the interactions between stromal cells and epithelial cells to inherited defects in DNA repair genes, such as BRCA1, BRCA2, and p53. However, the primary risk factors that have been identified are sex, age, childbearing, hormones, a high-fat diet, alcohol intake, obesity, and environmental factors such as tobacco use and radiation.
Yet, no aetiology is known for 95\% of breast cancer cases, while approximately $5 \%$ of new breast cancers are attributed to hereditary syndromes (2). In particular carriers of the breast cancer susceptibility genes, BRCA1 and BRCA2, are at a $30-40 \%$ increased risk for breast and ovarian cancer, depending on portion of the protein the mutation occurs (3).

Currently it is necessary that all breast cancers are tested for expression of the oestrogen receptor, progesterone receptor, and Human Epidermal Growth Factor receptor (HER2) proteins (4). The receptor profile of a given tumour helps predict its prognosis and helps the oncologist to choose the most appropriate treatment.

\section{Aetiological factors of breast cancer}

\section{Effects of certain drugs on breast cancer}

Inflammation contributes to the development of many diseases, including arthritis, atherosclerosis, and also its role in cancer has also been identified. But drugs with anti- inflammatory properties have not been proven to affect breast cancer. A study has revealed that aspirin appears to have no effect on the risk of getting breast cancer, which contradicts the results of earlier studies that suggested aspirin might help reduce that risk. Based on what we know now, taking aspirin is not an effective strategy to reduce the risk of breast cancer. Taking NSAIDs regularly for other medical reasons does not increase the breast cancer risk either $(5,6)$.

High blood pressure medications are given to millions of women around the world. With many women on high blood pressure medicine it makes sense to ask whether that medicine affects breast 
cancer risk. Researchers found no difference in breast cancer risk between women who took antihypertensive drugs and women who did not (7). But women with higher than normal diastolic blood pressure, who were not taking medicine to control it, were found to have a higher risk of breast cancer (8).

Statins lower LDL cholesterol in people whose cholesterol levels are high. In laboratory studies, statins have been shown to halt the growth, survival and migration of certain cancer cells. Though it is believed that statins on their own were associated with a reduction in breast cancer, recent study reviewed here found that statins had no effect at all on the risk of several cancers, including breast cancer $(9,10)$. The target enzyme for cholesterollowering statins, HMG-CoA Reductase is associated with improved prognosis among ERpositive breast cancer patients, whereas ER negative patients seem to have a better outcome when HMG-CoAR is absent (11).

Digoxin treatment has shown to increase the risk of invasive breast cancer among post-menopausal women (12).

Drugs used to treat female infertility do not appear to be associated with an increased risk of breast cancer $(13,14)$. The researchers found that clomephene and four synthetic hormones used to boost fertility did not significantly affect the risk of breast cancer $(15,16)$.

Tamoxifen has shown to reduce the incidence of oestrogen receptor positive breast cancer by approximately $50 \%$ in high risk women $(17,18)$. Similar results are seen for raloxifene which has a more favourable side-effect profile (19). Side effects appear to be fewer with the aromatase inhibitors, with no excess gynaecological (induced endometrial cancer) or thromboembolic events but an increase in fracture risk and joint symptoms does occur $(20,21)$.

\section{Hormone use and breast cancer}

Hormonal factors are implicated in tumour progression and it is possible that factors influencing breast cancer induction could affect prognosis.
Younger ages at menarche were significantly associated with higher grade tumours and increased risk of lymph node metastases (22).

Based on research, most healthcare professionals generally believed that using modern birth control pills (oral contraceptives) did not increase breast cancer risk, but researchers did find a slight increase in breast cancer risk in women who took birth control pills. However, the absolute risk, even for women mostly at risk, parous women and who used oral contraceptives for at least 4 years before their first full term pregnancy, was very small (23).

Post-menopausal hormone therapy has been a controversial issue with regard to breast cancer in the past. Previous studies suggest that only women who used the hormones for at least 5 years have an increase in breast cancer risk, but none have evaluated how shorter durations of use impact risk of lobular breast cancer. New research shows that women using combination HRT (hormone replacement therapy) for three or more years roughly triple their risk of 2 types of breast cancer: invasive lobular carcinoma and mixed ductallobular carcinoma. Therefore the current trend is for women considering hormone use should still try and use hormones for the shortest time possible and should use the lowest dose possible (24).

A number of reports in the early 2000s showed a higher risk of hormone-receptor-positive breast cancer in post-menopausal women who took combined HRT for an extended period of time. Since year 2000, use of HRT by post-menopausal women has decreased dramatically. A couple of years later, scientists noticed that cases of new breast cancers were also declining and rates of hormone-receptor-positive breast cancer also dropped. Decreased HRT use linked to decreased risk makes it very likely that HRT really affects breast cancer risk $(25,26)$,

Taking oestrogen only HRT for fewer than five years was not associated with an increased risk of breast cancer. When oestrogen only HRT was used for more than five years, breast cancer risk increased 
slightly (27). Also researchers have found that current, but not past use, compared to non usage of menopausal hormone therapy before diagnosis was shown to be associated with favourable tumour characteristics and survival (28).

\section{Mental illnesses and breast cancer}

A study reviewed here found that people diagnosed with schizophrenia were 3 times more likely to develop colon cancer and about 50\% more likely to develop breast cancer compared to people without schizophrenia. The higher rate of some common cancers in people with schizophrenia emphasizes the need for proactive monitoring of their physical health (29).

\section{Environmental factors affecting breast cancer}

One's personal risk of breast cancer is the result of many factors. Some of these factors such as the genes and the family history are things one cannot control. Others, such as what one eats, maintaining a healthy weight, and minimizing the exposure to chemicals in the environment, are things one can control.

Working in the clothing or textile industry, radiation exposure (a potential risk for women who work in hospital X-ray departments) and a family history of breast cancer, increase the risk of breast cancer. Eating a diet that is high in fiber and low in salt and working in an administrative position seems to reduce breast cancer risk.

High levels of sun exposure lowered the risk of breast cancer in the fair-skinned women by $47 \%$ compared to fair-skinned women who got less sun exposure. Exposure to high levels of sunlight didn't have the same benefit for women with darker skin. Vitamin D appears to be the link between sunlight and reduced risk, which is produced by the body with exposure to sunlight. Getting 10 minutes of sun rays on your face and hands each day gives you the benefits of sunlight without the risks (30).

\section{Pre-natal environment affects breast cancer risk in adulthood}

Researchers have shown that large birth size significantly increases subsequent risk for breast cancer in adulthood, independent of established risk factors. In addition, birth length and head circumference were also positively associated with breast cancer risk, leading the researchers to suggest that the pre-natal environment may influence breast cancer risk later in life.

Analysis of women with data from birth records showed that a $0.5 \mathrm{~kg}$ increase in birth weight was associated with an estimated 7\% increase in the risk for breast cancer.

Some speculate that the foetal hormonal environment associated with large birth size may alter programming of the breast, making it more susceptible to cancer initiation by endogenous hormone levels and other carcinogens later in life (31).

\section{Lack of sleep linked with breast cancer}

Women who get 6 hours of sleep or less a night face an increased risk for developing breast cancer compared with their peers who sleep more. A previous study reported that women with low levels of the sleep hormone, melatonin, have an increased risk for breast cancer.

Melatonin may have an inhibitory effect on gonadal function, including the synthesis and secretion of sex hormones, by promoting the release of gonadotropin-releasing hormone; it also exerts an antiproliferative effect on breast cancer cell lines (32).

\section{Link between obesity and cancer}

Keeping slim turned out to be one of the most important things a woman can do to lower the risk of cancer. Because the hormones that can influence breast cells and the development of breast cancer are made in fat tissue, excess body fat can increase a woman's chance of developing breast cancer after menopause (33). 
Overweight women have increased risk of getting breast cancer after menopause and being overweight can increase the risk of breast cancer coming back in women who have had the disease. This may be because fat cells make extra oestrogen and other hormones, which might stimulate breast cell growth. Excess weight can also make it harder to detect breast cancer early, when it's most treatable. Gaining weight after menopause seems to increase breast cancer risk in post-menopausal women. The good news is that weight loss was associated with a decreased risk of breast cancer (34).

\section{Exercise and breast cancer}

The studies reviewed here add to the growing amount of information on the role exercise can play in staying healthy. When it comes to exercise, more seems to be better. A study reviewed here reinforces the findings from a very similar study reviewed on Feb 21, 2007: regular strenuous exercise can lower your risk of breast cancer (35). Exercise may reduce cancer risk through changes in metabolism and the immune system, and by reducing weight gain (36). All needed for a significant reduction in breast cancer risk is,

A substantial weekly commitment (5 or more hours per week).

A strenuous routine (lap swimming, aerobics, running, kickboxing, etc.).

A regular routine that is done for years.

Researchers have found that even females with abnormal BRCA1 and BRCA2 genes benefit from exercise. So if they know that they have one of these abnomal genes, losing weight in their twenties, they may be able to lower the risk of developing breast cancer at a younger age (37).

\section{Habits}

The fluid in the breasts of women who smoke contains many of the same cancer causing substances found in tobacco smoke. This fact led scientists to suspect that smoking could increase breast cancer risk. Researchers have looked carefully at the link between breast cancer and smoking in young women. They found that smoking before childbearing years appears to increase the risk of breast cancer later in life. Women who had smoked for 10 pack-years before having their first child were $78 \%$ more likely to develop breast cancer than those who never smoked. There wasn't a link between breast cancer risk and smoking later in life. These results were inconsistent with the biologic data indicating that the female breast is sensitive to tobacco carcinogens before first childbirth (38). But researchers found that women who smoke are not more likely to have advanced breast cancer than women who do not smoke.

Drinking alcoholic beverages can increase breast cancer risk. How much alcohol is too much? The study found that alcohol consumption is associated with a linear increase in breast cancer incidence in women over the range of consumption reported by most women. Among women who consume alcohol regularly, reducing alcohol consumption is a potential means to reduce breast cancer risk (39). If you are interested in doing all you can to lower your risk of breast cancer or breast cancer recurrence, limiting your alcohol consumption makes sense. If you do enjoy alcoholic beverages and plan to continue using them, try to have fewer than 5 alcoholic drinks a week (40).

Researchers have found a link between coffee consumption, cytochrome P450 1A2 (CYP1A2) genotype, and breast volume, which could have implications for breast cancer development.

They show that coffee has a protective effect on breast cancer risk restricted to women with the CYP1A2*1F C-allele. Previous studies have reported that coffee may reduce the risk of breast cancer in women with the CYP1A2*1F C-allele but not in those with the CYP1 A2*1F A/A genotype. As breast volume is associated with breast cancer risk in lean women, our finding is compatible with earlier reports of a protective effect of coffee on breast cancer risk restricted to women with the CYP1A2*1F C-allele(41). One study suggest that coffee consumption reduces the risk of breast cancer in lean women, whereas coffee might have the opposite effect in relatively obese women (41). 


\section{Hair relaxers not seen linked to breast cancer}

Because African American women use chemical hair relaxers to straighten their hair more regularly than white women and because African American women are more likely to develop breast cancer before age 45 than white women, researchers wanted to know whether breast cancer was diagnosed more often in women who used hair relaxers. There was no evidence that the major ingredients in hair relaxers, such as lye and calcium hydroxide, promote cancer (42).

\section{Prevention}

To keep your risk of breast cancer or breast cancer recurrence as low as it can be, try to make choices that help control these factors:

- Figure out your ideal body weight and work hard to get there.

- Get 3 to 4 hours of moderate exercise per week.

- Eat a low-fat diet with 5-9 servings of fruits and vegetables a day.

- Avoid red and processed meats, simple carbohydrates and salt.

- Don't smoke, if you do smoke, quit.

- Avoid alcohol (if people must drink, they should limit their intake to 2 units per day for a man or one for a woman). Limit alcohol to less than 5 drinks a week.

- If you have a baby, breast-feed for at least the first 6 months.

- If possible, avoid hormone replacement therapy.

\section{References}

1. Pisani P, Parkin DM, Bray F, Ferlay J. Human cancer estimates of the worldwide mortality from 25 cancers in 1990. International Journal of Cancer 1999; 83: 18-29.

2. Madigan MP, Ziegler RG, Benichou J, Byrne C, Hoover RN. Proportion of breast cancer cases in the United States explained by well established risk factors. Journal of National Cancer Institute 1995; 87(22): 1681-5.
3. Venkitaraman AR. Cancer susceptibility and the functions of BRCA1 and BRCA2. Cell 2002; 108(2): 171-82.

4. Cavalieri E, Chakravarti D, Guttenplan J, et al. Catechol oestrogen quinones as initiators of breast and other human cancers: Implications for biomarkers of susceptibility and cancer prevention. Biochimica et Biophysica Acta (BBA) - Reviews on Cancer 2006; 1766(1): 63-78.

5. Kirsh VA, Kreiger N, Cotterchio M, Sloan M, et al. Non steroidal anti inflammatory drug use and breast cancer risk: subgroup findings. American Journal of Epidemiology 2007; 166(6): 709-16.

6. Cook NR, Lee IM, Gaziano M, Gordon D, et al. Low-Dose Aspirin in the Primary Prevention of Cancer: The Women's Health Study: A Randomized Controlled Trial. Journal of American Medical Association 2005; 294: 47-55.

7. Moysich KB, Beehler GP, Zirpoli G, Choi JY, Baker JA. Use of common medications and breast cancer risk. Cancer Epidemiology, Biomarkers, Prevention. 2008; 17(7):1564-95.

8. Lindgren A, Pukkala E, Tuomilehto J, Nissinen A. Incidence of breast cancer among postmenopausal, hypertensive women. International Journal of Cancer 2007; 121(3): 641-4.

9. Setoguchi S, Glynn RJ, Avorn J, Mogun H, et al. Statins and the risk of lung, breast, and colorectal cancer in the elderly. Circulation 2007; 115: 27-33.

10. Bonovas S, Filioussi K, Tsavaris N, Nikolaos Sitaras M. Use of statins and breast cancer: a meta-analysis of seven randomized clinical trials and nine observational studies. Journal of Clinical Oncology 2005; 23: 8606-12.

11. Borgquist S, Jogi A, Ponten F, Ryden L, et al. Prognostic impact of tumourspecific HMG-CoA reductase expression in primary breast cancer: breast cancer research 2008; 10(5): [About 11 screens] Available from: http://breast-cancerresearch.com/content/10/5/R79.

12. Ahern TP, Lash TL, Sørensen HT, Pedersen L. Digoxin treatment is associated with an increased incidence of breast cancer: a population-based case-control study. 
Breast Cancer Res. 2008; 10(6): [about 8 screens] Available from: http://breast-cancer-research. com/content/10/6/R 102

13. Klip H, Burger CW, Kenemans P, van Leeuwen FE. Cancer risk associated with subfertility and ovulation induction: a review. Cancer, Causes, Control 2000; 11(4): 319-44.

14. Orgéas CC, Sanner K, Hall P, Conner P, Holte J, Nilsson SJ, Sundfeldt K, Persson I, Chia KS, Wedren S, Dickman PW, Czene K. Breast cancer incidence after hormonal infertility treatment in Sweden: a cohort study. American Journal of Obstetrics and Gynecology 2009; 200(1): 72.e1-7.

15. Jensen A, Sharif H, Svare EI, Frederiksen K, et al. Risk of breast cancer after exposure to fertility drugs: results from a large Danish cohort study. Cancer Epidemiology, Biomarkers, Prevention 2007; 16: 1400-7.

16. Brinton LA, ScocciaB, Moghissi KS, Westhoff, $\mathrm{CL}$, et al. Breast cancer risk associated with ovulation-stimulating drugs. Human Reproduction 2004; 19(9): 2005-13.

17. Kinsinger LS , Harris R, Woolf SH, Sox HC, Lohr KN. Chemoprevention of Breast Cancer: a summary of the evidence for the U.S. Preventive Services Task Force. Ann Intern Med 2002; 137(1): 9-69.

18. Fisher B, Costantino JP, Wickerham DL, Redmond CK, Kavanah M, Cronin WM, Vogel V, Robidoux A, Dimitrov N, Atkins J, Daly M, Wieand S, Tan-Chiu E, Ford L, Wolmark N. Tamoxifen for prevention of breast cancer: report of the National Surgical Adjuvant Breast and Bowel Project P-1 Study. Journal of National Cancer Institute. 1998; 90(18): 1371-88.

19. Cummings SR, Eckert S, Krueger KA, et al. The effect of raloxifene on risk of breast cancer in postmenopausal women. Results from the MORE randomized Trial. Journal of American Medical Association 1999; 281: 2189-97.

20. Bonneterre J, Thürlimann B, Robertson JFR, et al for the Arimidex Study Group. Anastrozole versus tamoxifen as first-line therapy for advanced breast cancer in 668 postmeno-pausal women: results of the tamoxifen or arimidex randomized group efficacy and tolerability study. Journal of Clinical Oncology 2000; 22: 3748-57.

21. Forbes JF, Cuzick J, Buzdar A, et al for Arimidex, Tamoxifen, Alone or in Combination (ATAC) Trialists' Group. Effect of anastrozole and tamoxifen as adjuvant treatment for earlystage breast cancer: 100-month analysis of the ATAC trial. Lancet Oncol 2008; 9(1): 45-53.

22. Orgéas CC, Hall P, Rosenberg LU, et al. The influence of menstrual risk factors on tumor characteristics and survival in postmenopausal breast cancer. Breast Cancer Res 2008; 10(6): [about 9 screens] Available from: http://breastcancer-research. com/content/10/6/R 107.

23. Kahlenborn C, Modugno F, Potter DM, Severs WB. Oral contraceptive use as a risk factor for premenopausal breast cancer: A meta-analysis. Mayo Clinic Proceedings October 2006; 10: 1290-1302.

24. Li CI, Malone KE, Porter PL, et al. Relationship between meno-pausal hormone therapy and risk of ductal, lobular, and ductal-lobular breast carcinomas. Cancer Epidemiol, Biomarkers, Prev 2008; 17(1): 43-50.

25. Clarke CA, Glaser SL, Uratusu CS, et al. Recent decline in hormone therapy utilization and breast cancer incidence: clinical and population based evidence. Journal of Clinical Oncology 2006; 24: e49-e50.

26. Colditz GA. Decline in breast cancer incidence due to removal of promoter: Combination oestrogen plus progestin. Breast cancer research 2007; 9(4): 108. [about 3 screens] Available from: http://breast-cancer-research.com/content/ 9/4/108.

27. Rosenberg LU, Granath F, Dickman PW, Einarsdottir K, et al. Menopausal hormone therapy in relation to breast cancer characteristics and prognosis: A cohort study. Breast Cancer Research 2008; 10(5) (78). [about 11 screens] Available from: http://breastcancer-research.com/content/10/5/R78.

28. Cecilia Magnusson, Lars Holmberg, Torgny Nordén, Anders Lindgren, et al. Prognostic characteristics in breast cancers after hormone replacement therapy. Breast Cancer Research and Treatment 1996; 38(3): 325-34. 
29. Hippisly-cox J, Vinogradova Y, Coupland C, Parker C. Risk of malignancy in patients with schizophrenia or bipolar disorders: nested case control study. Archives of General Psychiatry 2007; 64(12): 1368-76.

30. Gorham ED, Garland FC, Garland CF. Sunlight and breast cancer incidence in the USSR. International Journal of Epidemiology 1990; 19(4): 820-4.

31. Park SK, Kang D, McGlynn KA, Garcia M, et al. Intrauterine environments and breast cancer risk: meta analysis and systematic review. Breast Cancer Res 2008; 10(1): [about 34 screens]. Available from: http://breast-cancerresearch.com/content/ 10/1/R 8.

32. Kakizaki M, Kuriyama S, Sone T, Matsuda KO, Hozawa A, Nakaya N, Fukudo S, Tsuji I. Sleep duration and the risk of breast cancer: the Ohsaki Cohort Study. British Journal of Cancer 2008: 99: 1502-5.

33. Dogan S, Hu X, Znang Y, Maihlie NJ, et al. Effect of high fat diet and/or body weight on mammary tumour leptin and apoptosis signaling pathway in MMTV - TGF- mice. Breast Cancer Research 2007; 9.

34. Chang SC, Ziegler RG, Dunn B, StolzenbergSolomon RS. Association of energy intake and energy balance with postmenopausal breast cancer in the prostate, lung, colorectal, and ovarian cancer screening Trial. Cancer Epidemiology, Biomarkers and Prevention 2006; 15: 334.

35. Peters TM, Schatzkin A, Gierach GL, Moore SC, et al. Physical Activity and Postmenopausal breast cancer risk in the NIH-AARP diet and health study. Cancer Epidemiol, Biomarkers, Prev 2009; 18(1): 289-96.
36. Campbell KL, McTiernan A. Exercise and biomarkers for cancer prevention studies. The Journal of Nutrition 2007; 137: 161S-9.

37. Wang M, Yu BK, Strange WR, et al. Prepubertal physical activity up-regulates estrogen receptor $\beta$, BRCA1 and p53 mRNA expression in the rat mammary gland. Breast Cancer Research and Treatment 2009; 115(1): 213-20.

38. Ha M, Mabuchi K, Sigurdson AJ, Freedman DM. Smoking cigarettes before first childbirth and risk of breast cancer. American Journal of Epidemiology Advance Access 2007 [About 7 screens] Available from: http//American Journal of Epidemiology, doi:10.1093/aje/ kwm045.

39. Smith-Warner SA, Spiegelman D, Yaun SS, et al, Alcohol and breast cancer in women: a pooled analysis of cohort studies. Journal of the American Medical Association 1998; 279(7): 535-40.

40. Jernström H, Henningson $\mathrm{M}$, Johansson U, et al. Coffee intake and CYP1A2*1F genotype predict breast volume in young women: implications for breast cancer. British Journal of Cancer 2008; 99: 1534-8.

41. Vatten LJ, Solvoll K, Loken EB. Coffee consumption and the risk of breast cancer. A prospective study of 14,593 Norwegian women. British Journal of Cancer 1990; 62(2): 267-70.

42. Rosenberg L, Boggs DA, Adams-Campbell LL, Palmer JR. Hair relaxers not associated with breast cancer risk: evidence from the black women's health study. Cancer Epidemiol, Biomarkers, Prev 2007; 16(5): 1035-7. 